\title{
Child - Parents Relations and the Success at School
}

\author{
Lyubov Vinnikova*
}

Research Centre for Pediatric Neuropsychology, Moscow

\begin{abstract}
The article highlights the empirical study. In which refers to children with learning difficulties at school. The types of child parent relationship in their families. Shows the effect of violations of child-parent relationships aggravating abnormalities in the formation of the VPF, and as a consequence, difficulties in school. Inadequate family relationships as partial cause disharmony in the emotional sphere of the child.
\end{abstract}

Keywords: Neuropsychology, type of family education, emotional and personality characteristics of children, school performance, learning difficulties.

\section{INTRODUCTION.}

L. S. Vygotsky was the first [1] to suggest that historical approach should become the leading principle for human typology creation. He gave theoretical criticism of biological, naturalistic notions of a human and opposed them with his theory of cultural and historic development, namely: mental processes are formed in the course of life and biological inherited features do not define mental abilities of a human being not contained virtually in his/her brain. Virtually brain implies only the ability to form mental processes. Specific human abilities and traits of a human are formed in the course of life in objective activities, in the communication process with the help of language.

L. S. Tsvetkova [2] in particular, note the great importance of these theoretical ideas for formation of correct understanding and solution to the problem of social and biological factors in a child's psychic. L. S. Vygotsky wrote about complexity and transformation of biological and social factors in the process of a child's development. He wrote about variety of combination of both processes determining specific features of each age stage in child's behavioral development and children's development types. Complex relations, combination of two diverse developmental pro-cesses biological and social - have a different value from the genetic point of view.

Most evident illustration of this may be found in such widespread phenomenon as school maladjustment. This notion includes social and environmental, psychological and pedagogical, medical and biological factors, or, to be exact, conditions of development of school maladjustment phenomenon itself. Family, where a child has been raised, and related emotional and personal features of such child play specific role in school maladjustment. Currently there are following approaches to understanding such complex

*Address correspondence to this author at the Russia, Moscow, Str. Saratovskaja, house 14/1; E-mail: micaella @mail.ru social and pedagogical phenomenon as SCHOOL MALADJUSTMENT based on different methodological grounds.

Position one: "School maladjustment" is a disorder of student's personality adaptation to the learning conditions at school, which is demonstrated as specific case of general mental adaptation disorder due to some pathologic factors. In this context school maladjustment is seen as medical and biological problem [3].

Position two. School maladjustment is a multifactor process of decrease and disturbance of a child's learning ability due to incompliance of learning process conditions and requirements of the closest social environment to his/her psychophysiological potential and needs [4]. This position reflects social maladjustment approach since main causes are sought from in the specifics of microsocial environment and inadequate conditions of school education. Unlike medical and biological concepts of school maladjustment this one has a positive feature of giving a priority to social and personal aspects of learning disorders in the analysis.

Position three. School maladjustment is mainly social and pedagogical phenomenon formed by combination of pedagogical and school factors [3]. Failure to satisfy personally valuable needs of a child at school, arising state of frustration tension and of mental discomfort with tendency to repetition and stereotyping - these are logical stages of formation of school maladjustment in such cases.

Position four. School maladjustment is a complex social and psychological phenomenon, the nature of which lays in impossibility for a child to find "his/her own place" in the space of school education where he/she would be accepted as they are keeping and developing his/her identity, potential self-fulfillment self-actualization opportunities. Main vector of this approach is directed at mental state of a child and psychological context of interdependence and intercondition of relations formed in the course of learning: "family-childschool", "child-teacher", "child-peers", "self preferred learning tactics - learning tactics employed at school". 
There are following maladjustment criteria:

\section{Academic failure}

\section{Distress of emotional and personal attitude to learning}

3. Repeated not controlled behavior disorders, including refusal to go to school

Among many social and biological factors providing for academic failure we assign quite important role to specifics of family interaction. Prof. Zh. M. Glozman wrote: "Interpersonal relations character and means of their demonstration that are specific for each family call forth patient's personality, be it an adult or a child, and further or inhibit mobilization of their abilities. Negative attitudes of some family members can lead to worsening of a child's mood and motivation for learning, cause withdrawal, unrealistic expectations, guilt feeling, hyperdependance, detachment and estrangement" [5]. Disorders of child-parent relations (rejection of a child by the parents, neglect, desolation; low esteem, repression out of personal problematic sphere, prevailing family achievement-oriented environment, hyperprotection by parents, spoiling, permissiveness, etc.) may be one of the causes for dysontogenesis [5-9].

To understand family interaction disorders more clearly we should consider its functions in more details. "Family is a social unit (small social group), most important form of organization of personal way of life based on marriage and kinship relations, i.e. relations between wife and husband, parents and children, siblings and other relatives living together in one household" [10]. Functions, structure and dynamics are most important features of a family.

Any family life sphere, closely related to satisfaction of specific needs of the family members, is called "family function". There are following functions: educational function; economical function; emotional function; communication function; initial social control function; sexual and erotic function. Family function disorder is a particularity of its life, which hinders or impedes the family functions implementation. Quite a range of factors may facilitate such disorders: specifics traits of the family members' personalities, relations inside the family, some conditions of life of the family. For example, lack of necessary knowledge and skill or distress in relations between the parents (conflicts in educational issues, impeding interference of other family members, etc.) may become a reason for educational family function disorder.

One of the most common typology of family interaction disorders is the one created by E. G. Eidemiller [11]:

Classification of types:

Encouraging hyper protection - child is the center of family attention, the family seeks to satisfy his/her needs to the maximum extent, this leads to development of demonstrative (hysteroid) and hyperthymic character traits.

Dominating hyper protection - child is also the center of family attention, however he/she is deprived of independence by many limitations and prohibitions, making emancipation response stronger and conditioning acute affective responses of extrapunitive type.
Emotional rejection - "Cinderella-type", forms and strengthens traits of epileptoid psychopathy and accentuation, leads to decompensation and formation of neurotic disorders.

Excessive moral responsibility - is characterized by combination of high demands with lack of attention from the parents, less care about the child. Development of traits of anxious apprehensive accentuation of character is stimulated.

Hypo protection - child is left all by himself/herself, parents do not express any interest in him/her, do not control him/her.

If we are to define symptomatology of family interaction disorders, we can mark out following predicators of emotional and behavioral disorders of children: Stressful atmosphere before childbirth; Tense relationships with the farther of future child; Unwillingness to have a child; Negative attitude of others towards the birth of the child; etc. Scare and fear of responsibility for the child; Lack of external support, depression of the mother; Financial problems; Negative risk factors in the family or in educational institution; affective conflicts between spouses and misunderstanding of child's state; Inability to create corrective and developing environment for the child; Rigid, formal, superficial communication with the child in the family; Lack of consideration (extraversion, introversion, ambiversion) or specific features of the child; Early mother's return to work (child of less than 3 months old; Inadequate response of the parents to intellectual failures of the student; Excessive demands to the child; Early start of formal education; Excessive complexity of educational curriculum; Misunderstanding of behavioral disorders and children's "nervousness" as laziness by parents or teachers.

\section{RESEARCH DESIGN}

Our research proved that a significant part of children with learning problems (38\%) had a difficult family situation often conditioned by distressed child-parents relations as a ground of severe failure of a child at school, difficult relations with adults in family, with teachers at school and sometimes even with peers.

Role of family interaction may be seen in more details through examples of defining different "psychological syndromes of academic failure". Mental characteristics construing the syndrome, behavioral manifestations and typical response of the adults to these manifestations have become the basis for this typology [12].

Chronic academic failure and school anxiety. Significant increase of anxiety level is the key factor. It is related to negative feedback from the adults on first academic failures that are almost inevitable in the beginning of study. As the result child's self-confidence goes down and anxiety goes up. This leads to deterioration of results, disorganization of activities, waste of time, etc. Fear of mistakes leads to unreasonable efforts for checks made over and over again. Pathological circle is created: activity disturbance - failure - negative feedback from others - anxiety. There is also one more important trait inherent in the syndrome - high level of socialization and conformity of a child, habit to obey, 
non-critical fulfillment of demands. If there is no such orientation, such child is indifferent to his failures to some extent.

Anxious activity disorganization (i.e. disorganization caused by high level of anxiety) is the most important sign of the syndrome. There is one more condition apart from increased anxiety - high level of socialization and conformity of a child, habit to obey, non-critical fulfillment of demands. In some cases excessive expectations of parents turn out to be the "weak link" triggering this vicious circle. In case of expectations gap on the part of parents chronic failure may be formed as early childhood. Also it is possible that excessive anxiety of child due to the influence of family conflicts or wrong upbringing style may be the initial source.

\section{RETREAT FROM ACTIVITY}

Development of this type occurs, as a rule, if a child doesn't get enough attention from adults. This may be explained by family troubles or (more often) by an excessive child's need for attention. This is the development type of a child, which is unable to realize ostentation he/she possesses. Retreat from activity means retreat to an inner reality, to playing fantasy formation. Negative outcomes of such retreat are multiple knowledge gaps, difficulties in full realization of potentials. Retreat from reality is characterized by the following combination of traits (or parents complaints): passivity of a child, demonstration of ostentation, inclination to fantasy formation, anxiety.

\section{NEGATIVE AND POSITIVE SELF-PRESEN- TATION}

These types of development occur if a child has especially high need of attention from others (i.e. with distinct ostentation).

Negative self-presentation. If a child is unable to attract necessary attention of others he/she sometimes chooses the way of conscious breach of rules of behavior, which is always a reliable means. Paradoxically enough the forms of treatment used by adults as means of punishment turn out to be an incentive for such child. The only true punishment is the deprivation of attention. It is harder to get positive response than negative and a child chooses the easiest way, and negative response from adults serve as a support to his/her provoking display of behavior.

Positive self-presentation. This syndrome is close to the previous one, but the attention is drawn to a child not through breach of rules, but rather through emphasized obedience. However, it is often enough that such children are unbearable in everyday life. The reasons is that the parents, once got used to "ideal" behavior of their child, simply stop to pay attention to him/her. In order to get the attention back such child has to use different means, for example, those borrowed from the store of negative self-presentation.

\section{SOCIAL DISORIENTATION.}

This syndrome occurs as the result of dramatic shifts of a child's life conditions. It may be, for example, entering a school or change of school. However, only children with decreased sensitivity to social norms are prone to this syndrome. Impulsiveness and hyperactivity are a fertile ground for social disorientation, since these traits rapidly increase number of conflicts with social norms. The most important thing, which is distressed in case of social disorientation, is the understanding of hierarchy, relative social value of different norms (acts as a list of equal rules, such as "no fidgeting at a lesson, no running during a break, and no walking out of class even if you are not interested in what the teacher is talking, no hitting your classmate if he/she's calling you and so on"). This syndrome is characterized by combination of such traits as complaints about breach of social norms by a child, low level of socialization, lack of antisocial sets.

\section{VERBALISM AND INTELLECTUALISM.}

This syndrome is the only one related by the authors to specific features of cognitive development .

Verbalism. This psychological syndrome is characterized by prevalence of verbal development over development of other cognitive processes. It is related to emphasis on child's speech development on the part of adults, and, as the result, steal from other activity types, so imaginative thought suffers. Such children are successful in the very beginning of study due to the knowledge they've already obtained, and the formality of such knowledge is found later. However very soon the trouble begins when the tasks become more complex. Inability to clearly orientate activities and unformed thinking become evident. Parents often explain this by low level of development of other children. However the fact is that many significant mental processes are underdeveloped.

Intellectualism is characterized by well-developed logical thinking (distinctly higher than average age level) with underdeveloped imaginative thought, perception, and motor functions, as a rule. Such children have rare problems with scholarship, because they meet main requirements to the logical thinking, which is the strength of such a child. Personality of such children is emotionally infantile, since it gets further from children's activities.

\section{FAMILY ISOLATION}

This psychological syndrome is actually a "sticking" of a child in the family relations system appropriate for the preschool age, when the family is the main sphere of his/her communications. Belonging of a family to some minority, such as: religious sect, ethnical or national minority, specific ideological, cultural or political movement is a frequent ground for this syndrome. In all these cases inclusion of a child into social reality is hindered by strong differences between family values and prevailing social beliefs. 


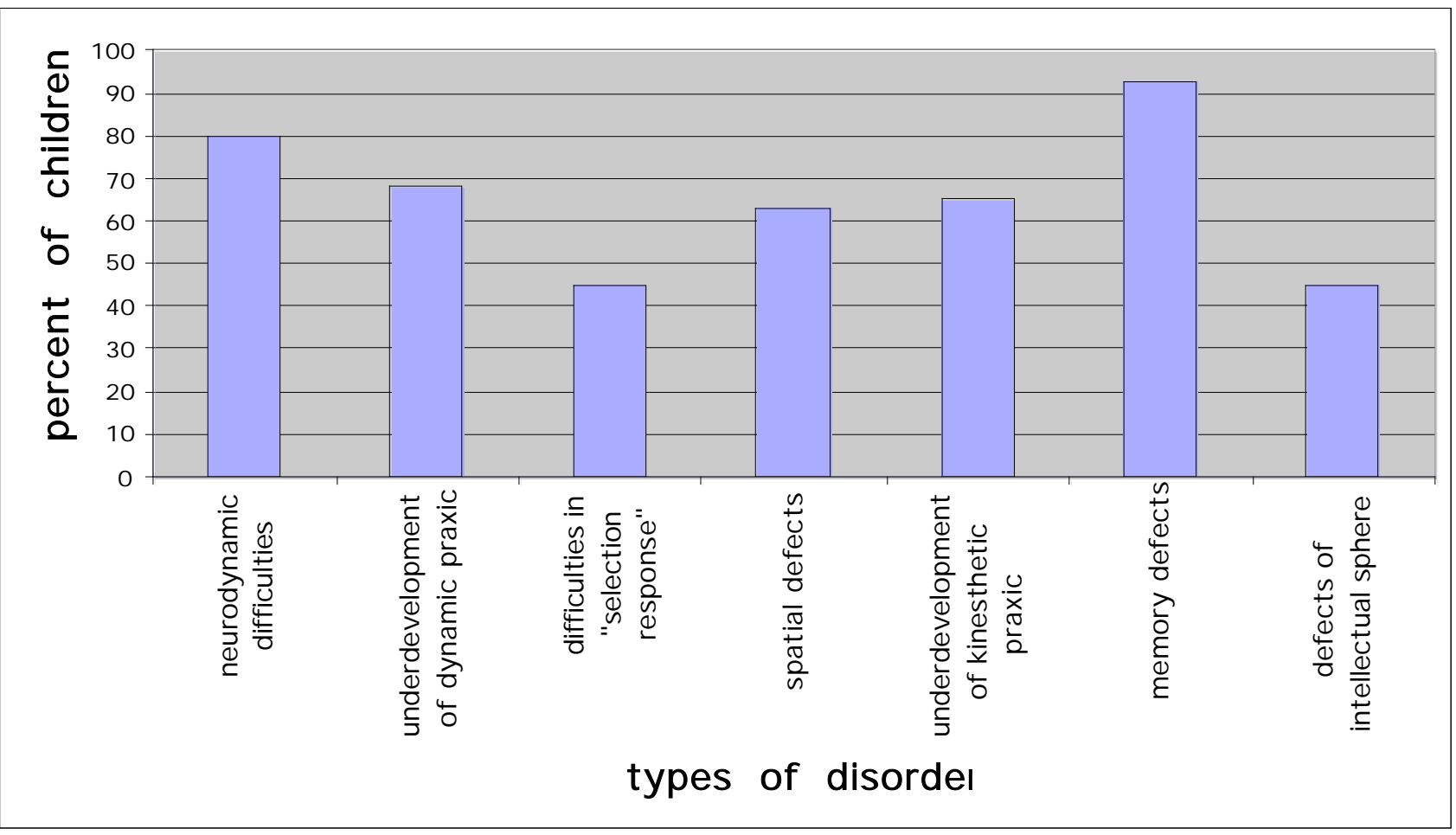

Fig. (1). Neuropsychological profile of children.

Psychological peculiarities inherent in the family isolation are high dependence of a child and infantilism. As the result such a child does not develop communication skills and his withdrawal to the family relations sphere gets further. Family history, data on the family lifestyle and system of relations with a child are very important in order to diagnose this syndrome.

Independently on the key factor remediation of such a child includes orientation on two interrelated sets of issues.

I set - higher mental functions and mental abilities development in junior school students.

II set - correction of emotional and personal specific features of the students.

Mediated remediation, based upon Vygotsky's principles, is done through correction of pedagogical stand of parents and teachers through mandatory inclusion of the family into different types of activities that may range from simple educational workshop and training for parents to family psychotherapy.

A research conducted in our Research center of developmental neuropsychology confirms the above stated data. The purpose of this research was an experimental study of specific features of child-parent relations in families raising children with learning problems at school due to an underdevelopment of some mental functions

Three methodological complexes were used in our experimental research:

1. Assessment of parent's personality traits:Mini-Mult questionnaire -(a MMPI short form [13]; Study of parents' estimation of themselves, of a child's father and of a child [14];
2. Analysis of family relations: "Family Relations Questionnaire" by E.G. Eidemiller [11]; projective method "A Life Story with a Problematic Child" [15]; Analysis of parents' answers to Early Child Development questionnaire (presence of gaps, "not remembering" indirectly point on lack of attention to a child in a family);

3. Assessment of child's cognitive, emotional and personal features: neuropsychological assessment (Luria method); Color-Drawing Test [16]; Real and ideal selfesteem evaluation [12]. We studied 2 groups of qualities: child's personal traits and educational and social activity. School Anxiety Test [16].

Forty families with school age children having underdeveloped higher mental functions took part in our research. Protocols of neuropsychological assessment stated at least one mental area with symptoms of underdevelopment not less than the score 1.5 points, which corresponds to medium to high level of development deficiency. [6].

\section{RESULTS}

Though the higher mental functions underdevelopment of children from experimental group was of complex character and affected all functional links, it was possible to identify key tier of underdevelopment in neuropsychological profile (Fig. 1).

Almost all children (92.5\%) had difficulties with memorizing and storing of information of different modality, $80 \%$ had neurodynamic difficulties (decrease and instability of mental performance and attention span), more than a half of junior school students had underdeveloped dynamic, kinesthetic and spatial components of mental activity. $22.5 \%$ of 40 examined families revealed distinct family upbringing 


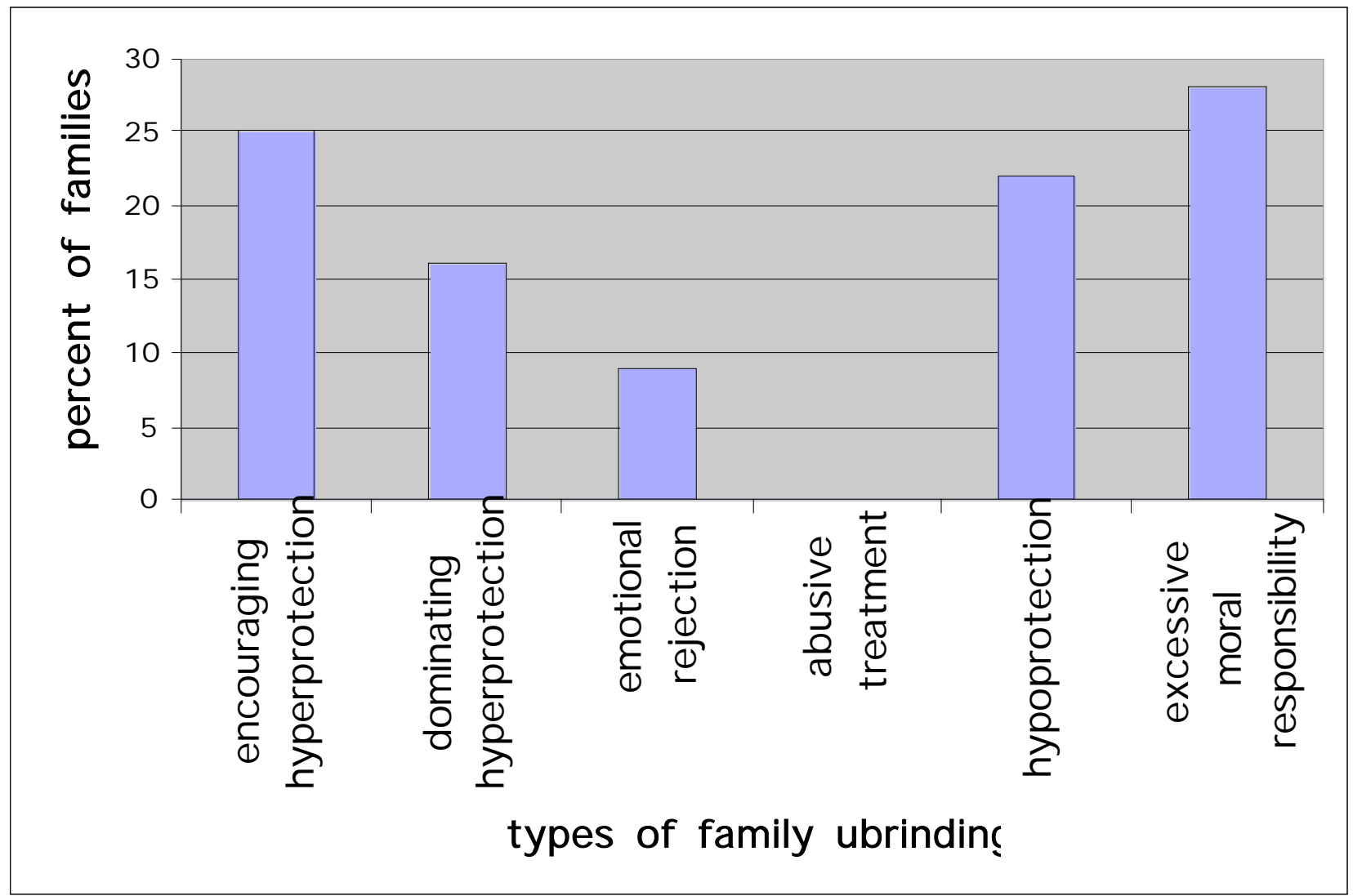

Fig. (2). Types of family interaction.

disorders. Excessive moral responsibility was most common type of disorder, encouraging hyper protection or hypoprotection (Fig. 2).

Comparison of this data with the results of self-esteem analysis shows that families with encouraging hyper protection had distinctly overstated evaluation of a child by his/her parents by all measures with adequate self-esteem or evaluation of other parent. Unreasonably high self-esteem is evident in affective sphere of such a child. In evaluation of school difficulties these children did not demonstrate any significant decline, and this is an evidence of general lowering of criticism for their school difficulties and of placing "locus-control" to the outside.

In the families with dominant hyper protection disorder the children are more infantile comparing to the previous group, but they are also more critical. Thus in their evaluation of school difficulties the children demonstrated general fear of self-expression and fear of exams situations. Only these children revealed underdeveloped verbal function in neuropsychological assessment - naming problems, difficulties in constructing sentences, We may suppose that this type of family upbringing disorder hinders verbal development of a child.

In the families with high score on "excessive moral responsibility" evaluation of children was either adequate or low with high self-evaluation or evaluation of the other parent at the same time. Naturally it affected the emotional state of children. They've shown low-self-esteem. The tests show general tiredness and fatigability, school anxiety, fear of not meeting others' expectations in these children.

Families tending to hypo protection demonstrate stable medium type of evaluation of their children and themselves, parents don't emphasize any difficulties or conflicts in family caused by their child's problems. Such families come to workshops rarely, allow a lot of gaps in child's development questionnaire, which are difficult to fill even after personal conversation. In affective sphere evaluation children' despondency, tiredness, general detachment, and general school anxiety come to the view.

\section{CONCLUSION}

- Academic failure is a complex multifactor phenomenon, where family influence and specific features of child-parent relations are intervened with many biological preconditions.

- Types of family influence distress together with different social and pedagogical factors form specific syndromes of "psychological" academic failure.

- Learning problems entails specific deviations of emotional and personal sphere.

- Inclusion of parents and family in the remediation process for school maladjustment treatment is a necessary condition to overcome learning problems. 


\section{CONFLICT OF INTEREST}

The author confirms that this article content has no conflicts of interest.

\section{ACKNOWLEDGEMENTS}

Declared none.

\section{REFERENCES}

[1] Vygotsky LS. Biogenetic law in psychology and pedagogy. Moscow: Great Soviet Encyclopedia 1927; 6; 257-79.

[2] Kotyagina SN, Tsvetkova LS. Actual problems of pediatric neuropsychology: Textbook for Universities. Moscow: MODEK 2006.

[3] Kovalev VV, Ed. Problems in the prevention and rehabilitation of Suicidology. Collection of scientific papers. Moscow: Publishing House of the Institute of Psychiatry 1984.

[4] Severny AA, Skoblo GV, Balandina TA. Mental disorders in children in the first years of life and mental health of their parents. Moscow: Institute of Humanity of the Russian Academy of Sciences 1995.
[5] Glozman JM. Communication disorders and personality. Moscow: Academy Press 2002.

[6] Glozman JM. Developmental Neuropsychology. Moscow: Academy Press, 2009.

[7] Kiessling L. The neuropsychology of childhood learning and school behavior. In: Tupper D., Cicerone K., Eds. The neuropsychology of everyday life: issues in development and rehabilitation. Boston: Kluwer Academic Publishers, 1990; pp. 17-45.

[8] Ooki S. Genetic and environmental influences on stuttering and tics in Japanese twin children. Twin Res Hum Genet, 2005, 8, 1: 69-75.

[9] Sapir SG, Nitzburg AC, Eds. Children with learning problems. New-York: Brunner Mazel 1973.

[10] Solovev NY. Marriage and family today. Mintis: Vilnius 1977.

[11] Eidemiller EG, Yustitskis VV. Family psychotherapy. Petersburg: Peter, St 2009.

[12] Wenger AL, Zuckerman GA. Psychological examination of schoolchildren. Moscow: Vlados 2007.

[13] Mironova E. Collection of psychological tests. Minsk: ENVILA 2005.

[14] Rubinstein SY. Experimental procedures in psychopathology. Medicine: Moscow 1970.

[15] Tkacheva VV. Technology of psychological study of families with children with developmental disabilities. Moscow: SAG 2006.

[16] Prokhorov AO. St Petersburg: Workshop on psychology states. Speech 2004.

(C) Lyubov Vinnikova; Licensee Bentham Open.

This is an open access article licensed under the terms of the Creative Commons Attribution Non-Commercial License (http://creativecommons.org/licenses/by$\mathrm{nc} / 3.0 /$ ), which permits unrestricted, non-commercial use, distribution and reproduction in any medium, provided the work is properly cited. 